\title{
CONCEITOS DE LEITURA EM DOCUMENTOS OFICIAIS NACIONAIS E ESTADUAIS
}

Concepts of reading in national and state official documents

Conceptos de la lectura en los documentos oficiales nacionales y estatales

\section{Rosyanne Fonseca da Silva ${ }^{* 1}$, Ângela Francine Fuza ${ }^{2}$}

${ }^{1}$ Graduada em Letras, Universidade Federal do Tocantins, Tocantins, Brasil.

${ }^{2}$ Docente do curso e do Programa de Pós-Graduação em Letras, Universidade Federal do Tocantins, Tocantins, Brasil.

* Coordenação do curso de Letras. Rua 03, Quadra 17, Lote 11, S/N ${ }^{o}$, Setor Jardim dos Ipês. Porto Nacional, Tocantins, Brasil. CEP: 77500-000.E-mail: annefon22@hotmail.com

\section{Artigo recebido em 20/04/2016 Aprovado em 25/05/2016 Publicado em 23/09/2016.}

\section{RESUMO}

O objetivo desta pesquisa é analisar os conceitos de leitura demarcados por documentos oficiais nacionais e estaduais que subsidiam a prática da leitura no contexto escolar. O estudo se pauta nos pressupostos da Linguística Aplicada sobre a leitura, sobre a concepção dialógica de linguagem e nas pesquisas desenvolvidas no Brasil sob essa vertente. Primeiramente, abordam-se os pressupostos sobre leitura apresentes nos documentos nacionais: Parâmetros Curriculares Nacionais do Ensino Fundamental (BRASIL, 1998) e Parâmetros Curriculares Nacionais do Ensino Médio (BRASIL, 2000); na sequência, aqueles presentes nos documentos estaduais: Referencial Curricular do Ensino Fundamental das Escolas Públicas do Estado do Tocantins (TOCANTINS, 2009a) e Proposta Curricular do Ensino Médio (TOCANTINS, 2009b). Os resultados da pesquisa documental apontam que, de forma geral, o conceito de leitura que constitui os documentos oficiais analisados é a perspectiva interacionista, pois a leitura é concebida como um processo que possibilita o diálogo entre autor, texto e leitor, contribuindo para formação do leitor crítico.

Palavras-chave: Leitura; Conceito; Documento oficial.

\section{ABSTRACT}

The aim of this research is to analyze the concept of reading in the mainly official documents that subsidize the practice of reading in the school context. The work is guided on the assumptions of Applied Linguistics about reading, about dialogical conception of language and research developed in Brazil under this line. First of all, it is pointed out the assumptions about Reading showed in the national documents: Parâmetros Curriculares Nacionais do Ensino Fundamental (BRASIL, 1998) and Parâmetros Curriculares Nacionais do Ensino Médio (BRASIL, 2000); after, the ideas presented by state documents: Referencial Curricular do Ensino Fundamental das Escolas Públicas do Estado do Tocantins (TOCANTINS, 2009a) and Proposta Curricular do Ensino Médio (TOCANTINS, 2009b). The results of the documentary research show that, in general, in the official documents there is the interactive concept of reading, since reading is conceived as a process that enables dialogue between author, text and reader, contributing to the formation of the critical reader.

Keywords: Reading; Concept; Official document.

\section{RESUMEN}

El objetivo de esta investigación es analizar los conceptos de lectura marcadas por los documentos oficiales nacionales y estatales que apoyan la práctica de la lectura en el contexto escolar. El estudio se guía en los supuestos de la lingüística aplicada sobre la lectura en la concepción dialógica del lenguaje y de la investigación desarrollada en Brasil en esta partida. En primer lugar, se abordan los supuestos sobre apresentes de lectura en documentos nacionales: básicos Parámetros Curriculares Educación (Brasil, 1998) y Parámetros Curriculares Nacionales para la Educación Secundaria (BRASIL, 2000); como resultado, los presentes en los documentos del 
Estado: Referencia Curricular de la Educación Básica del Estado de las Escuelas Públicas de Tocantins (Tocantins, 2009a) y Curriculum Propuesta de Educación Secundaria (Tocantins, 2009b). Los resultados de la investigación muestran documental que, en general, se analiza el concepto de lectura de documentos oficiales es la perspectiva interaccionista, porque la lectura se concibe como un proceso que permite el diálogo entre el autor, el texto y el lector, lo que contribuye a la formación lector crítico.

Palabras clave: Lectura; concepto; documento oficial.

\section{INTRODUÇÃO}

Com as experiências, promovidas pelas disciplinas de Prática de Ensino e Estágio Supervisionado em Língua Portuguesa, na Licenciatura Letras, foi possível constatar que grande parte dos alunos, seja do ensino fundamental ou do médio, apresentam dificuldades nas atividades de leitura em sala de aula.

No contexto escolar, a leitura e a escrita são fundamentais em qualquer uma das disciplinas, por isso, em cada ano estudado, o aluno precisa desenvolver capacidades, habilidades e estratégias de ler e de escrever, para atender às demandas curriculares (MENEGASSI; FUZA, 2010). No âmbito da escola, os documentos oficiais são instrumentos que fundamentam o trabalho do professor em relação à prática da leitura, por exemplo. É necessário, então, evidenciar concepções claras do que seja a leitura, principalmente, por parte dos formuladores e implantadores de políticas públicas, pois "os documentos ecoam na sala de aula" (FIAD, 2012, informação verbal), ou seja, percebemse diálogos entre as práticas escolares e os documentos que norteiam o processo de ensino e de aprendizagem. Logo, os formuladores precisam ter clareza no entendimento dessas concepções, sempre relacionando as práticas de leitura presentes no contexto escolar e extraescolar.

Embora este estudo foque na leitura, tendo em vista seu objetivo e extensão do texto, ressalta-se que ela é entendida como uma das práticas que compõem o processo de ensino de língua materna em sala de aula, dialogando com as práticas de produção de texto e de análise linguística. Caso o professor, munido dos discursos dos documentos oficiais, conduza a prática da leitura pelo viés dialógico de linguagem, há a possibilidade de, consequentemente, haver o trabalho com a escrita e a análise linguística de forma contextualizada, levando à formação do leitor e do escritor competentes. Logo, faz-se relevante o estudo dos documentos oficiais.

Diante do exposto, esta pesquisa, resultado de um Trabalho de Conclusão de Curso de Licenciatura em Letras, analisa os principais documentos oficiais do Brasil que fundamentam a prática da leitura, a fim de verificar os conceitos de leitura por eles demarcados. Sendo assim, os documentos oficiais nacionais selecionados são: os Parâmetros Curriculares Nacionais do Ensino Fundamental - PCN (BRASIL, 1998) e os Parâmetros Curriculares Nacionais do Ensino Médio - PCNEM (BRASIL, 2000). Além deles, em âmbito estadual, selecionam-se: o Referencial Curricular do Ensino Fundamental das Escolas Públicas do Estado do Tocantins - RCEF (TOCANTINS, 2009a) e a Proposta Curricular do Ensino Médio - PCEM (TOCANTINS, 2009b).

Esta pesquisa foi realizada à luz de algumas teorias da Linguística Aplicada, tendo por pressupostos o interacionismo, na perspectiva sóciohistórica da linguagem, a partir de Bakhtin e dos pesquisadores brasileiros que seguem esta vertente (DELL'ISOLA, 1996; FUZA, 2010; LEFFA, 1996; KLEIMAN, 2000; 2010; MENEGASSI, ANGELO, 
2005). Caracteriza-se como uma pesquisa documental (CELLARD, 2008), tendo em vista o foco em documentos oficiais, por meio da análise de conteúdo (SILVA, ALMEIDA, GUINDANI, 2009), ou seja, segmentos específicos foram selecionados de acordo com a frequência na qual o tema "leitura" era percebido nos documentos.

Este artigo, vinculado ao projeto de pesquisa: "A escrita em contextos de ensino e de aprendizagem" (UFT), discorre, primeiramente, a respeito dos pressupostos teóricos sobre leitura; na sequência, destaca a análise dos documentos oficiais e, por fim, a conclusão.

\section{CONCEPÇÕES DE LEITURA: ALGUMAS PERSPECTIVAS}

A temática sobre o trabalho com a leitura é algo recorrente na literatura (MENEGASSI; ANGELO, 2005; FUZA, 2010; LEFFA, 1996, dentre outros). Para Menegassi e Angelo (2005, p. 15), por exemplo, os estudos a respeito da leitura vinculam-se ao desenvolvimento da própria Linguística. Houve o enfoque, inicialmente, no estudo das unidades isoladas da língua, como sons, palavras etc. e, com o desenvolvimento das pesquisas das ciências da linguagem, como "a Linguística, a Psicolinguística, o Gerativismo, a Sociolinguística, a Pragmática, a Linguística Aplicada", dentre outras, o foco foi sendo alterado, chegando ao texto como unidade comunicativa e as suas condições de produção.

Ao tratar da leitura, os autores afirmam que teorias que atribuem papel ao leitor e ao seu conhecimento foram reconhecidas com o passar do tempo, mas continuam ainda, no contexto escolar, estudos com foco no texto, na extração de ideias. Sendo assim, postulam-se perspectivas de leitura: perspectiva do texto, perspectiva do leitor e perspectiva interacionista (MENEGASSI; ANGELO, 2005).

De acordo com Fuza (2010, p. 12), há diferentes denominações para as perspectivas, como "leitura sob a perspectiva do texto; leitura como extração; leitura como decodificação". A leitura centrada no leitor é denominada: "leitura sob a perspectiva do leitor; leitura como atribuição". Conforme a autora, "no processo de leitura as perspectivas destacadas não ocorrem de forma isolada, não são meramente etapas sucedendo umas às outras, uma vez que as práticas de leitura exigem o contínuo diálogo entre autor-texto-leitor" (FUZA, 2010, p. 12). Evidencia-se, então, segundo a estudiosa, que "uma visão não exclui a outra, mas sim, possibilita a efetivação do processo de leitura como interação” (p. 12).

A partir da abordagem dos conceitos de leitura pelos teóricos da Linguística Aplicada, ter-seá fundamentos para a discussão e para a análise dos documentos oficiais do Brasil e do Tocantins, a fim de verificar os conceitos de leitura por eles demarcados.

$\mathrm{Na}$ perspectiva do texto, o ato de ler é visto como processo de decodificação de letras e sons e o texto é processado em sua linearidade, uma vez que a leitura não é um processo ativo em que o leitor busca e traz informações para o texto. Leffa (1996) considera esse modo de conceber a leitura como sendo um processo de extração de significado, associada à ideia de que o texto tem um significado preciso, exato e completo que deve ser apreendido pelo leitor na sua íntegra.

Segundo Kleiman (2010), a maioria das atividades que enfoca a leitura como extração faz que essa prática sirva como forma de avaliar, de mensurar uma decodificação para saber se o aluno entendeu o texto, isto é, se ele é capaz de repetir ideias prontas de um determinado enunciado. Segundo a autora, 
nessa perspectiva, o objetivo da leitura é apenas de identificação do conteúdo do texto, em um processo mecânico. Logo, essa perspectiva é criticada por não levar em consideração construção de sentido da leitura, centrando no texto um significado completo, não necessitando do leitor.

Diferentemente da primeira perspectiva, na perspectiva do leitor, o foco recai no papel do leitor que atribui informações ao texto. $\mathrm{O}$ significado desponta do leitor para o texto, através de hipóteses, adivinhações etc. A crítica que se faz a essa perspectiva de leitura, segundo Menegassi e Angelo (2005), é que, embora o leitor ganhe um papel ativo atribui significado, faz previsões sobre o que será lido - os aspectos sociais são descartados, há uma confiança exagerada nas adivinhações do leitor, possibilitando qualquer interpretação do texto. Diante da necessidade de valorização da leitura do aluno, "toda e qualquer interpretação passa a ser considerada legítima. Se a interpretação do aluno não corresponde à do professor, prevalece a interpretação do aluno, já que é ele o leitor" (MENEGASSI; ANGELO, 2005, p. 15).

$$
\text { Kato (1990) apresenta algumas }
$$

características que definem o leitor-atribuidor como aquele que tira suas conclusões apressadas, por meio de adivinhações que não são verificadas e deixa de processar informações secundárias relevantes para a compreensão global do texto.

Logo, percebe-se juntamente com os teóricos que as duas perspectivas de leitura apresentam seus conceitos de estudo: o texto e o leitor. A primeira foca no texto, vendo-o como produto finalizado e a segunda perspectiva destaca o papel do leitor em atribuir um significado para aquilo que lê, seus conhecimentos de mundo são considerados, indo além da decodificação e da extração de informações.

A perspectiva interacionista, como o próprio nome diz, postula a interação entre leitor e texto (autor), promovendo um diálogo e a construção de uma compreensão e de uma resposta ativa ao que está exposto.

Segundo Fuza (2010), a leitura realizada de forma interativa possibilita ao aluno o seu amadurecimento como sujeito crítico que não apresenta como sua opinião o discurso expresso pelo professor em sala. $\mathrm{Na}$ perspectiva interacionista, a leitura passa por fases: extração de significados, à atribuição de informações para, então, haver um diálogo que leva em consideração conhecimento prévio e texto. Assim, deve haver o diálogo entre as perspectivas de leitura, permitindo que o aluno aja ativamente diante do texto, demonstrando compreensão e resposta ativas ao que lhe é solicitado.

Conforme Leffa (1996), no complexo processo de leitura, é preciso considerar, então: (a) o papel do leitor, (b) o papel do texto e (c) o processo de interação entre o leitor e o texto. Leitura implica uma correspondência entre conhecimento prévio do leitor e os dados fornecidos pelo texto.

$\mathrm{Na}$ concepção interacionista, a leitura encontra sua razão de ser na busca pelas transformações da realidade, fazendo que o cidadão aja criticamente e transforme o meio social em que se encontra, desmascarando-se a ideologia dominante, que dita aquilo que é correto ou não, segundo seus pressupostos. Ela é responsável, pois abala "o mundo das certezas, elabora e dinamiza conflitos, organiza sínteses, enfim combate assiduamente qualquer tipo de conformismo, qualquer tipo de escravização às ideias referidas pelo texto" (SILVA, 1998, p. 26).

Segundo Zygmantas e Freitas (2003/2004, p.17), “a leitura crítica do mundo implica agir nele, transformando-se a si mesmo e o mundo que nos cerca". Ao ler um texto, o leitor se depara com diferentes informações que interagem com os conhecimentos já tidos, promovendo uma leitura interativa. Efeito da interação entre sujeito/linguagem 
gerado pela leitura, tem-se o leitor como coprodutor do texto, completando-o com sua bagagem históricocultural (DELL'ISOLA, 1996). Pois os conhecimentos de mundo irão preceder a leitura da palavra, ou seja, do texto e quanto mais se tem diversas leituras, mais conhecimentos emais chances tem o cidadão de mudar a perspectiva de mundo.

Embora a prática da leitura, fundamentada nos princípios interacionistas, possibilite $\mathrm{o}$ crescimento e o desenvolvimento de um aluno-leitor crítico, é possível ainda constatar a persistência quanto ao método tradicional, por meio do qual professor e conhecimentos são vistos como autoridade, assim como sua metodologia de ensino.

Tal quadro necessita ser repensado, pois, a partir da leitura crítica do texto, promovida e estimulada pelo professor mediador que partilha a responsabilidade do aprendizado da leitura com os alunos (KEZEN, 2005), o estudante compreende ativamente o enunciado e consegue "responder ativamente" (BAKHTIN, 2003) ao que foi exposto, confirmando ou refutando as ideias que surgiram durante a interação. Logo, a leitura realizada de forma interativa permite ao aluno o seu amadurecimento como sujeito crítico que não apresenta como sua opinião o discurso expresso pelo professor em sala.

Leffa (1996) argumenta que a leitura deve ser o meio que promove a interação entre o leitor e o texto, elaborando uma compreensão através das trocas de conhecimentos e informações realizadas pelos participantes do discurso. $\mathrm{O}$ ensinoaprendizagem da leitura expõe que o significado do enunciado é construído mediante o processo de interação entre leitor e texto, produzindo-se um momento de diálogo caracterizado como visão interacionista, pois:

\begin{abstract}
a leitura acontece ao desencadear-se o processo criativo em que sujeito e linguagem interagem permanentemente, uma vez que o texto nunca está acabado, não é produto, antes, dispositivo de produção. [...]. A leitura produto é pessoal, individual, determinada pelas condições sociais, culturais, históricas, afetivas e ideológicas do leitor, portanto, é variável, porque o texto apresenta lacunas que convidam o leitor a preenchê-las (DELL'ISOLA, 1996, p. 73).
\end{abstract}

A perspectiva interacionista pressupõe o papel do leitor como ser participativo: ele busca informações, extrai dele o que condiz com seu objetivo, atribui seu conhecimento prévio e produz um sentido. $E$ por meio da interação entre sujeito/linguagem, gerada pela leitura, tem-se o leitor como coprodutor do texto, completando-o com sua bagagem histórico-cultural (DELL'ISOLA, 1996).

A partir do exposto, verifica-se que a leitura, na perspectiva interacionista, promove o diálogo entre as diferentes concepções de leitura, possibilitando a formação e o desenvolvimento de um leitor crítico.

Sendo assim, diante da relevância dos estudos sobre as perspectivas de leitura, opta-se por verificar de que forma são contempladas em quatro documentos oficiais brasileiros, a saber: a) PCN (BRASIL, 1998); b) PCNEM (BRASIL, 2000); c) RCEF (TOCANTINS, 2009a); d) PCEM (TOCANTINS, 2009b).

\section{LEITURA NOS DOCUMENTOS OFICIAIS}

Leitura nos Parâmetros Curriculares do Ensino Fundamental

Em relação ao ensino e à aprendizagem da leitura, os PCN (BRASIL, 1998, p. 40) utilizam a expressão "trabalho com a leitura" destacando que na formação de leitores competentes é preferível o desenvolvimento de uma atividade no coletivo, envolvendo, por meio do texto, professor, aluno e 
autor. Segundo Menegassi e Fuza (2010, p. 317), "observa-se que a leitura é tida como um processo, ou seja, constituída de etapas que exigem um trabalho de construção de significado do texto por parte do leitor".

Em relação à perspectiva de leitura interacionista, os PCN (BRASIL 1998, p. 41) compreendem que a leitura é concebida como processo, pois o leitor realiza um trabalho ativo de "construção do significado do texto, a partir de seus objetivos, do seu conhecimento sobre o assunto [...] não se trata simplesmente de extrair informações da escrita, decodificando a letra por letra, palavra por palavra". Assim, o processo de construção de sentido leva o autor à compreensão. Sendo assim, a leitura perpassa etapas e o significado é constituído pelo leitor que "extrai as ideias, faz sua compreensão e, a partir disso, produz os sentidos possíveis para o texto que leu" (MENEGASSI; FUZA 2010, p. 318).

O aluno, no processo de leitura, extrai as ideias, faz sua compreensão e, em seguida, produz os sentidos prováveis ao texto lido. Os PCN (BRASIL, 1998) afirmam que é importante superar algumas concepções sobre o aprendizado inicial da leitura: a principal delas é a de que ler é simplesmente decodificar, converter letras em sons, sendo a compreensão consequência natural dessa ação. Por conta desta concepção equivocada, a escola vem produzindo grande quantidade de "leitores" capazes de decodificar qualquer texto, mas com enormes dificuldades para compreender o que tentam ler (BRASIL, 1998, p. 43).

Outro aspecto abordado pelos PCN (BRASIL, 1998) é o trabalho com a leitura que deve ser diário, sugerindo, pois, que a leitura pode ser realizada de forma silenciosa, individualmente, em voz alta em grupo ou individual ou pela escuta de alguém que lê. Ao mesmo tempo, alerta para alguns cuidados quanto a essas sugestões: toda atividade de leitura em voz alta necessita anteriormente suscitar sentido para o aluno; nas atividades de leitura sempre explicar os objetivos e preparar o aluno; refletir com os alunos diferentes modalidades de leitura.

Observa-se que, para a formação de leitores competentes, o aluno tem que realizar um trabalho ativo nesse processo. Desse modo, constata-se que os PCN (BRASIL, 1998) apresentam o aluno como um dos membros da leitura, pois ela é tida como um processo; o leitor realiza um trabalho ativo, constrói significados do texto, tem objetivos de leitura e não apenas extrai informações do texto, mas também as compreende.

No que se refere às atividades de leitura, o trabalho de reflexão sobre a língua é importante por possibilitar a discussão sobre diferentes sentidos atribuídos aos textos e sobre os elementos discursivos que validam ou não essas atribuições de sentido (BRASIL, 1998). Menegassi e Fuza (2010) refletem:

se o indivíduo utiliza a leitura como uma forma de ação nas situações presentes no seu contexto social, não se pode, então, considerá-la como repetição infindável de atividades escolares que visam, por exemplo, a uma única forma de leitura ou ao preenchimento de fichas exaustivas. Dessa forma, a prática constante de leitura na escola pressupõe o trabalho com a diversidade de objetivos, modalidades e textos (MENEGASSI; FUZA 2010, p. 319).

Conforme os PCN (BRASIL, 1998), a leitura é concebida, então, como uma forma de interação, decorrente de várias etapas até chegar a sua interpretação. Diante dos aspectos teóricos apresentados no referido documento, destacam-se, na sequência, por meio do Quadro 1, as características teóricas sobre a concepção de leitura que o perpassa. 
Quadro 1. Características teóricas sobre a leitura nos PCN (BRASIL, 1998).

A leitura leva à formação e ao desenvolvimento de leitores competentes.

A leitura é um processo coletivo.

A leitura é constituída de etapas;

O leitor realiza um trabalho ativo de construção do significado do texto.

O leitor tem objetivos de leitura.

A leitura implica compreensão.

A leitura é concebida como uma forma de interação.

Fonte: Elaboração própria.

Conforme exposto, compreende-se que nos PCN (1998), a leitura tem como foco a formação de um leitor crítico, respeitando-se seu conhecimento prévio no processo de leitura.

\section{Leitura nos Parâmetros Curriculares do Ensino Médio}

Os PCNEM (BRASIL, 2000), em relação ao ensino da Língua Materna, iniciam expondo uma síntese das teorias desenvolvidas sobre o processo de ensino e de aprendizagem: "o estudo da língua materna na escola aponta para uma reflexão sobre o uso da língua na vida e na sociedade" (PCNEM 2000, p. 16). Logo, percebe-se que uma das funções da escola prevê trabalhar os conteúdos em sala de aula dialogando com o contexto social do aluno.

Outro aspecto abordado é em relação à comunicação que é entendida como "processo de construção de significados em que o sujeito interage socialmente, usando a língua como instrumento [...] A língua é compreendida como linguagem que constrói e "desconstrói" significados sociais" (BRASIL 2000, p. 17). A partir de outras leituras, de seu conhecimento prévio e da sua leitura de mundo, o sujeito entra no processo de construção de significados, elaborando seu próprio conhecimento. Entende-se, então, que tanto a comunicação como a leitura tem importância fundamental na vida das pessoas.

Quanto à leitura nos PCNEM, são realizadas menções bem pontuais e sintetizadas, como:

os conteúdos tradicionais de ensino da língua, ou seja, nomenclatura gramatical e história da literatura são deslocadas para um segundo plano. O Estudo da gramática passa a ser uma estratégia para uma compreensão/interpretação/produção de textos e a literatura integra-se a área de leitura (BRASIL 2000, p. 18).

O simples fato de decodificar já não é suficiente, é necessária a interação entre textos e leitores, assim, o ensino da gramática deve ser realizado por meio da leitura e da escrita de textos, de forma contextualizada. Tal fato ilustra as ideias propostas por Geraldi (2008):

o ensino de língua portuguesa deveria centrar-se em três práticas: leitura de textos; produção de textos; e análise linguística. Essas práticas, integradas no processo de ensino-aprendizagem, têm dois objetivos interligados: a) tentar ultrapassar, apesar dos limites da escola, a artificialidade que institui na sala de aula quanto ao uso da linguagem; b) possibilitar, pelo uso não artificial da linguagem, o domínio efetivo da língua padrão em suas habilidades oral e escrita (GERALDI, 2008, p. 88).

Em relação à interação, os PCNEM (BRASIL, 2000, p. 18) apontam que ela é responsável por fazer: “com que a linguagem seja comunicativa. Esse princípio anula qualquer pressuposto que tenta referendar o estudo de uma língua isolada do ato interlocutivo". Nesse caso, a partir de uma concepção dialógica de linguagem, a prática da leitura, consequentemente, passa a ser concebida como um processo, assim como Leffa (1996, p. 22) postula: "leitura implica uma correspondência entre conhecimento prévio do leitor e os dados fornecidos pelo texto [...] leitor e texto são 
como duas engrenagens correndo uma dentro da outra".

Os PCNEM também refletem sobre como compreender os discursos por meio da intertextualidade:

Disciplinas nas áreas das Ciências Humanas e suas Tecnologias podem ajudar em muito tal compreensão. Relacionar os discursos com contextos sócio-históricos, ideologias, simulacros e pensar os discursos em sua intertextualidade podem revelar a diversidade do pensamento humano. Deve-se compreender o texto que nem sempre se mostra, mascarado pelas estratégias discursivas e recursos utilizados para se dizer uma coisa que procura "enganar" o interlocutor ou subjugá-lo. Com, pela e na linguagem as sociedades se constroem e se destroem. É com a língua que as significações da vida assumem formas de poesia ou da fala cotidiana nossa de cada dia (BRASIL 2000, p.19).

Diante do exposto, não necessariamente direcionado à leitura, entende-se que, para a realização do ensino e da aprendizagem, faz-se necessário contextualizar as aulas e aproveitar as experiências de vida dos alunos. Para isso, é preciso abertura de diálogo entre os envolvidos.

O PCNEM (2000, p. 19) não especificam as práticas de leitura, de escrita e etc. em seções, mas sim, são objetivadas em tópicos como: "competências e habilidades a serem desenvolvidas no processo de ensino/aprendizagem, ao longo do Ensino Médio". Assim, no ensino de língua, as habilidades de falar, ouvir, ler e escrever são fundamentais e devem ser trabalhadas constantemente. Dessas habilidades, os PCNEM (BRASIL, 2000) apresentam quatro eixos organizadores:

considerar a Língua Portuguesa como fonte de legitimação de acordes e condutas sociais e como representação simbólica de experiências humanas manifestas nas formas de sentir, pensar e agir na vida social(p. 20);

analisar os recursos expressivos da linguagem verbal, relacionando textos/contextos, mediante a natureza, função, organização, estrutura, de acordo com as condições de produção/recepção (intenção, época, local, interlocutores participantes da criação e propagação de ideias e escolhas) (p. 20);

confrontar opiniões e pontos de vista sobre as diferentes manifestações da linguagem verbal e compreender (p. 21);

usar a Língua Portuguesa como língua materna, geradora de significação e integradora da organização do mundo e da própria identidade (p. 22).

No terceiro eixo, compreende-se o "confrontar opiniões e pontos de vistas" como uma forma de abordar a leitura. A respeito disso, os PCNEM apresentam:

Consciente e responsável, o aluno poderá fazer previsões e escolhas adequadas na fala/escrita, bem como olhar para o texto de forma crítica, ampliando os significados para além da palavra escrita. Poderá ver-se no texto e ver o texto como objeto, dialogar com o "outro" que o produziu, criar seu próprio texto (BRASIL, 2000, p. 22)

Uma vez que há o diálogo, têm-se experiências a serem "trocadas", enriquecendo, assim, os saberes. Logo, em decorrência dessa integração entre os envolvidos que se faz sugerir a motivação necessária e transformadora.

Outro aspecto citado sobre leitura no ensino da língua materna é o uso da língua segundo o PCNEM:

o uso da língua só pode ser social e o social, longe de ser linear, leva a intricadas redes de significações. De qualquer forma o sujeito que produz a linguagem é único, bem como a situação de produção. $\mathrm{O}$ uso depende de se ter conhecimento sobre o dito/escrito (leitura/análise) a escolha de gêneros e tipo de discursos (BRASIL, 2000, p. 22).

Percebe-se a importância de apresentar várias leituras, para que sejam refletidas no uso da língua no ambiente social. O sujeito, ao produzir seu discurso, de acordo com sua situação de produção, retoma leituras e conhecimentos para compor sua fala, sendo 
assim, há um diálogo entre textos já lidos e interlocutores.

Nos PCNEM (BRASIL, 2000), não são constatadas seções sobre leitura, escrita e análise linguística, assim como ocorre nos PCN (BRASIL, 1998. De forma geral, verifica-se a exposição da leitura de forma fragmentada, cabendo ao leitor buscar e complementar as informações sobre ela. A linguagem é tida como interação, como fruto de diálogo e, consequentemente, ler é visto como prática que relaciona discursos, textos, possibilitando ao aluno desenvolver um olhar crítico a respeito do que lê.

A partir do exposto, destacam-se no Quadro 2, as características de leitura presentes nos PCNEM (BRASIL, 2000):

Quadro 2. Características teóricas sobre a leitura nos PCNEM (BRASIL, 2000).

\begin{tabular}{l}
$\begin{array}{l}\text { Gramática é é para } \\
\text { compreensão/interpretação/produção de textos. }\end{array}$ \\
\hline Literatura integra-se a área de leitura. \\
\hline $\begin{array}{l}\text { A leitura está centrada na visão de linguagem como } \\
\text { interação. }\end{array}$ \\
\hline Leitura leva à interação entre textos e discursos. \\
\hline Leitura deve levar à formação do leitor crítico. \\
Fonte: Elaboração própria.
\end{tabular}

A leitura é entendida como meio de interação, cabendo ao leitor relacionar os conhecimentos teóricos e os seus conhecimentos prévios.

\section{Leitura no Referencial Curricular do Ensino Fundamental do Tocantins}

De acordo com o RCEF (TOCANTINS, 2009a), o ensino de Língua Materna, quanto à leitura, deve apresentar como um dos pontos essenciais para a exploração do texto: "levar o aluno a perceber as marcas deixadas pelo autor" (TOCANTINS, 2009a, p. 260). Essa citação demarca uma característica da perspectiva do texto, pois, segundo Leffa (1996, p.
13), uma das características do processo de leitura como extração de significados é "a leitura como processo ascendente. A compreensão sobe do texto ao leitor na medida exata em que o leitor vai avançando no texto". Dessa forma, o aluno lê o texto, extraindo dele as ideias que foram deixadas pelo autor, cabendo ao sujeito retirá-las do texto.

Ao mesmo tempo, o RCEF (TOCANTINS, 2009a) apresenta características que correspondem à perspectiva do leitor, pois: “o educando não deve ser induzido no seu processo de análise e reflexão do texto, para não impedi-lo de uma apropriação particular do mesmo". Durante o processamento do texto, o leitor não joga somente com aquilo que está claramente explícito na materialidade textual, mas também com um mundo de informações implícitas, não expressas no texto, mas imprescindíveis para poder compor o significado (FULGÊNCIO; LIBERATO, 1996). O leitor carrega consigo informações subentendidas conhecidas como conhecimento prévio, consequentemente, na realização da leitura, extrai o que é posto na materialidade linguística.

Ao observar os objetivos da Língua Portuguesa no ensino fundamental, apenas um deles trata da leitura:

1. Utilizar a linguagem na escuta e produção de textos orais e na leitura e produção de textos escritos, de modo a atender as múltiplas demandas sociais, respondendo a diferentes propósitos comunicativos e expressivos, considerando as diferentes condições de produção do discurso [...] ( TOCANTINS, 2009a, p. 261).

O que se percebe é que a leitura é um dos objetivos do ensino da Língua Portuguesa e que ela deve estar voltada para atender as demandas sociais e para responder aos propósitos comunicativos presentes nas situações de uso da linguagem. Tendo em vista tais particularidades, o RCEF (TOCANTINS, 2009a) aborda como competências a 
serem contempladas no ensino fundamental: prática de escuta de textos orais; prática de leitura de textos; prática de escrita e produção de textos e prática de análise linguística.

Em relação a contextualizar a leitura no ensino da Língua Materna, menciona-se a necessidade da abordagem de "textos de vários gêneros para o desenvolvimento das habilidades de leitura [...] para as diferentes situações de intercâmbio comunicativo" (TOCANTINS, 2009a, p. 263). Ao considerar que a leitura deve ser trabalhada de forma a atender as demandas da sociedade, é coerente o enfoque atribuído aos gêneros, tendo em vista que representam modos culturais e sociais de uso da linguagem.

O RCEF (TOCANTINS, 2009a, p. 338) também apresenta as "Orientações Didáticas" em relação à leitura: "a leitura de textos escritos é muito mais que uma atividade de decodificação, ou seja, é uma atividade que implica estratégias de seleção, antecipação, inferência e verificação”. Constata-se, então, a postura interacionista no trato de tal prática, haja vista que a decodificação é tida como parte de um processo maior de trabalho com a leitura, não sendo o seu único objetivo. Logo, a leitura é um processo que perpassa estratégias, ou seja, é construída processualmente pelo leitor. Sendo assim, algumas sugestões didáticas são mencionadas pelo documento, como a leitura autônoma, a leitura colaborativa, a leitura em voz alta, a leitura de escolha pessoal, dentre outras.

As sugestões didáticas, de acordo com a forma de organização feita pelo professor, podem levar a uma leitura interativa, pois ele pode começar fazendo o aluno realizar uma leitura autônoma e tópica, na qual deve extrair do texto o que ele acha importante; depois, em grupo, o aluno pode partilhar e atribuir informações ao texto, dialogando, construindo o seu sentido. $\mathrm{O}$ fato de destacar também a leitura de escolha pessoal (leitura de fruição) é algo relevante para desenvolver no aluno o gosto pela leitura.

Em relação a essa concepção, Geraldi (2008) aponta que esse tipo de leitura pode, além de privilegiar o gosto pela leitura, transformar aos poucos os hábitos dos alunos. A princípio toda leitura que é cobrada se torna algo pesado e não prazeroso de realizar. O autor ainda afirma ser necessário "recuperar na escola e trazer para dentro dela o que dela se excluiu por princípio - o prazer - me parece o ponto básico para o sucesso de qualquer esforço honesto de "iniciativa à leitura"' (GERALDI, 2008, p. 98).

Com as sugestões do RCEF (TOCANTINS, 2009a), quanto ao ensino da língua materna, pode-se constatar que se o professor tomar uma das orientações de forma isolada recairá na tradição. A ideia das orientações é que ele as utilize e monte um conjunto de atividades. Logo, se as perspectivas de leitura forem trabalhadas isoladamente, nunca se chegará à interação, pois uma depende da outra para que haja um todo.

Ao propor orientações que encaminham para uma leitura processual, perpassando as fases de decodificação, de atribuição, para se alcançar a interação, constata-se que o RCEF (TOCANTINS, 2009a) dialoga diretamente com os postulados dos PCN (BRASIL, 1998), uma vez que também postula a necessidade de ultrapassar a visão de leitura somente como decodificação, fato tão corriqueiro no contexto atual de ensino. Diante do exposto, por meio do Quadro 3, destacam-se as características presentes no RCEF (TOCANTINS, 2009a). 
Quadro 3. Características teóricas sobre a leitura nos PCEF (TOCANTINS, 2009a).

A leitura deve levar o aluno a perceber marcas do autor.

A leitura não deve ser induzida a fim de que o aluno realize seu processo de apropriação do texto.

A leitura deve ser realizada a partir de textos simples para os textos de maior complexidade.

A leitura para entender as demandas sociais.

A leitura de vários gêneros deve ser contemplada.

A leitura é mais que uma atividade de decodificação.

A leitura implica estratégias de seleção, antecipação, inferência e verificação.

A leitura pode ser trabalhada por meio das diferentes sugestões didáticas.

Fonte: Elaboração própria.

Para o RCEF (TOCANTINS, 2009a), a leitura é parte de um processo de amadurecimento do leitor, dialogando com a perspectiva interacionista.

\section{Leitura na Proposta Curricular do Ensino Médio}

\section{do Tocantins}

Em relação ao ensino e à aprendizagem da leitura da disciplina Língua Portuguesa, a PCEM (TOCANTINS, 2009b) traz como foco principal desenvolver a proficiência de leitura e de escrita, contribuindo para a autonomia dos sujeitos, para a capacidade de análise crítica e de transformação da realidade. Mostra também que a leitura é concebida como um processo de interlocução, em que o leitor busca significações e reconstrói o texto, atribuindolhe sentido a partir de outras leituras, do seu conhecimento prévio e da sua leitura de mundo.

Essa visão de leitura como interação é proposta também pelos documentos de âmbito nacional, já que a consideram como processo ativo, no qual o leitor realiza um trabalho de construção de significado do texto, busca extrair, primeiramente, um significado já existente para depois produzir um sentido, a partir de seus objetivos e do seu conhecimento prévio.
Este documento ressalta que vem sendo enfatizado o tratamento didático da leitura na prática pedagógica dos professores. Logo, o trabalho com a leitura pode permitir ao aluno a reflexão a respeito das diversas questões sociais que o cerca, auxiliandoo a buscar informações e orientações para a solução de um problema (TOCANTINS, 2009b).

Essa noção expressa pelo documento dialoga com os postulados trazidos no RCEF (TOCANTINS, 2009a), pois percebe a leitura como um processo que deve envolver o aluno em questões da realidade, possibilitando-lhe atuar em seu contexto social por meio da leitura de textos que nele circulam. O leitor constrói o sentido dos textos, articula seus saberes aos novos estudados, atuando como um sujeito ativo, como um leitor crítico e não passivo "que se constitui como sujeito perante o texto" (TOCANTINS, 2009b, p. 211).

Segundo o documento, alguns critérios devem ser somados a outros referentes à realidade da escola, como a consideração das experiências socioculturais dos leitores, a fim de propor leituras que tratem dos seus anseios:

considerando que o aluno do Ensino Médio frequenta diversos espaços de socialização e de cultura juvenil [...] as práticas de leitura e produção de textos em gêneros diversos precisam considerar esse contexto, para que não seja fragmentada a relação entre o que se faz na escola e o que é produzido no contexto social (TOCANTINS, 2009b, p. 223).

A partir dessas ideias, observa-se que a leitura deve considerar a vida social do aluno, bem como seus conhecimentos prévios não somente no contexto escolar, mas também social e individual.

Como a leitura tem que se tornar algo prazeroso, a PCEM (TOCANTINS, 2009b) apresenta algumas orientações didáticas, como: recursos didáticos que considerem as necessidades dos jovens que já são produtores de textos em suas relações 
sociais; fazer conexões entre as atividades de leitura, produção textual e análise linguística. Assim,

O trabalho com a leitura na sala de aula requer a abordagem do texto em diferentes dimensões: linguística (recursos linguísticos em uso), textual (configuração do texto em gêneros discursivos ou sequências textuais), sóciopragmática e discursiva (relacionada aos interlocutores e seus papeis sociais, à situação e ao momento histórico e social), cognitivo conceitual (associada aos conhecimentos de mundo que envolvem os conceitos e suas interrelações) (MEC/SEB, 2006). As atividades devem focalizar não apenas a formação ou a consolidação do gosto pela leitura, mas, sobretudo o desenvolvimento da capacidade de compreensão do texto escrito (TOCANTINS, 2009b, p. 213).

A PCEM (TOCANTINS, 2009b) propõe a leitura por meio de diversos textos, permitindo ao leitor as possibilidades de criar e de recriar, saindo do tradicional: ler para decodificar letras e saber pronunciar. Em relação a isso, o documento traz uma proposta do Ministério da Educação (MEC):

O estudo de diferentes relações intertextuais, por exemplo, entre textos que mantenham configuração formal similar, que circulem num mesmo domínio ou em domínios diferentes, que assumam um mesmo ponto de vista no tratamento do tema ou não, é uma outra possibilidade de análise nas atividades de leitura de textos escritos ou na escuta de textos orais (MEC/SEB, 2006) (TOCANTINS, 2009b, p. $214)$.

Essa relação intertextual proporcionará uma interação entre o leitor e o conhecimento, o que é uma das características da concepção interacionista, pois toda vez que o texto é lido pelo leitor em momentos diferentes apresentará novas descobertas: "toda compreensão da fala viva, do enunciado vivo é de natureza ativamente responsiva, toda compreensão é prenhe de resposta" (BAKHTIN, 2003, p. 271). A respeito disso, Fuza (2010) aborda que a visão interacionista de ensino-aprendizagem da leitura expõe que o significado do enunciado é construído mediante o processo de interação entre leitor e texto, produzindo-se um momento de diálogo, não mais um produto pronto, acabado, pois "o texto, unidade complexa de significação, instaura um espaço de interlocução no qual intervêm elementos contextuais e intertextuais, uma vez que é resultado de absorções e transformações de outros textos" (DELL'ISOLA, 1996, p. 71).

A leitura deve dialogar com as outras práticas de linguagem como as propostas de análise linguística. A leitura contextualiza o trabalho com a análise, permitindo atividades como a leitura e a comparação de textos, bem como a reescrita dos textos, possibilitando ao aluno perceber as várias formas de estruturar os períodos e ligá-los por meio de operadores argumentativos, sendo capazes de escolher entre as diversas possibilidades da língua a que melhor atende ao sentido que deseja. Contudo, "o desafio do professor está em sinalizar as diversas relações que a linguagem estabelece, ligando os conhecimentos culturais e sociais que permeiam as situações comunicativas e possibilitando ao aluno uma leitura crítica da realidade" (TOCANTINS, 2009b, p. 234).

Nesse sentido, observa-se a necessidade de priorizar as atividades de leitura e de produção de textos em uma relação transformadora quanto ao trabalho conjunto de leitura, produção de texto e análise linguística levando sempre em consideração a situação real do aluno.

Por meio do exposto, destacam-se as características de leitura presentes na PCEM (TOCANTINS, 2009b): 
Quadro 4. Características teóricas sobre a leitura na PCEM (TOCANTINS, 2009).

A leitura contribui para a autonomia dos sujeitos, para a capacidade de análise crítica.

A leitura é um processo de interlocução.

A leitura permite refletir sobre questões da realidade que cercam o aluno.

A leitura permite ao aluno buscar informações e orientações para solucionar problemas.

A leitura deve considerar as experiências dos leitores/alunos.

A leitura vai além da decodificação.

A leitura envolve dimensões linguística textual, discursiva dentre outras.

A leitura deve focar na consolidação do gosto pela leitura e no desenvolvimento da compreensão do texto.

A leitura envolve relações intertextuais.

A leitura deve levar o aluno a ler criticamente a realidade.

Fonte: Elaboração própria.

A leitura é algo muito amplo, não pode apenas ser considerada como uma interpretação de palavras transformadas em som (decodificação), contribuindo para a autonomia dos sujeitos.

\section{CONCEITO DE LEITURA NOS DOCUMENTOS OFICIAIS NACIONAIS E ESTADUAIS}

No decorrer da análise dos quatro documentos oficiais investigados, observou-se, em todos eles, a perspectiva de leitura interacionista. Com as discussões da literatura de Linguística Aplicada e teóricas já sistematizadas, a partir dos teóricos e pesquisadores brasileiros que seguem esta vertente Leffa (1996), Menegassi e Angelo (2005), Kleiman (2010), Fuza (2010), foi possível o levantamento de algumas características básicas do conceito de leitura como interação, elencadas no Quadro 5, em um contraponto com aquelas observadas nos documentos oficiais.

De forma geral, na perspectiva da leitura interacionista é levado em consideração o texto, as informações que o cercam, bem como o conhecimento prévio do leitor, gerando, assim, a construção de sentido e a apropriação de novas culturas. Logo, os documentos analisados tanto do Ensino fundamental como do Médio apoiam que o ato de ler deve ser instigado no aluno desde os anos iniciais: "[...] a interação sujeito/linguagem na leitura é caracterizada por uma situação de intersubjetividade do leitor/texto que se relacionam durante a enunciação, ambos com identidades sociais próprias" (MAGALHÃES, 1996, p. 72).

$\mathrm{O}$ ato da leitura é muito mais do que simplesmente ler um artigo de revista, um livro, um jornal. Ler se tornou uma necessidade, é participar ativamente de uma sociedade, desenvolver a capacidade verbal, descobrir o universo através das palavras.

\section{CONSIDERAÇÕES FINAIS}

Este trabalhou analisou os principais documentos oficiais do Brasil e do Estado do Tocantins que fundamentam a prática da leitura no contexto escolar, a fim de verificar os conceitos de leitura por eles demarcados. A partir da análise constata-se que os documentos dialogam no sentido de que todos tratam de alguma forma, da leitura como processo ativo do leitor. Ademais, a leitura é abordada como um processo e não apenas como um procedimento mecanizado, por meio do qual o leitor identifica as palavras e as pronuncia. 
Quadro 5. Perspectiva interacionista nos documentos oficiais.

\begin{tabular}{|c|c|c|c|c|}
\hline $\begin{array}{l}\text { CARACTERÍSTICAS } \\
\text { TEÓRICAS }\end{array}$ & PCN (1998) & PCNEM (2000) & RCEF (2009a) & PCEM (2009b) \\
\hline $\begin{array}{l}\text { - A leitura realizada de forma } \\
\text { interativa possibilita ao aluno } \\
\text { o seu amadurecimento como } \\
\text { sujeito crítico que não } \\
\text { apresenta como sua opinião o } \\
\text { discurso expresso pelo } \\
\text { professor em sala. }\end{array}$ & $\begin{array}{l}\text { A leitura leva à } \\
\text { formação e ao } \\
\text { desenvolvimento } \\
\text { de leitores } \\
\text { competentes. }\end{array}$ & $\begin{array}{l}\text { Gramática é } \\
\text { estratégia para } \\
\text { compreensão/inter } \\
\text { pretação/produção } \\
\text { de textos. }\end{array}$ & $\begin{array}{l}\text { A leitura deve levar } \\
\text { o aluno a perceber } \\
\text { marcas do autor. }\end{array}$ & $\begin{array}{l}\text { A leitura contribui } \\
\text { para a autonomia } \\
\text { dos sujeitos, para a } \\
\text { capacidade de } \\
\text { análise crítica. }\end{array}$ \\
\hline $\begin{array}{l}\text { - Leitura que permite que o } \\
\text { aluno aja ativamente diante do } \\
\text { texto. }\end{array}$ & $\begin{array}{l}\text { A leitura é um } \\
\text { processo coletivo. }\end{array}$ & $\begin{array}{l}\text { Literatura integra- } \\
\text { se a área de } \\
\text { leitura. }\end{array}$ & $\begin{array}{l}\text { A leitura não deve } \\
\text { ser induzida a fim } \\
\text { de que o aluno } \\
\text { realize seu processo } \\
\text { de apropriação do } \\
\text { texto. }\end{array}$ & $\begin{array}{l}\text { A leitura é um } \\
\text { processo de } \\
\text { interlocução. }\end{array}$ \\
\hline $\begin{array}{lr}\text { - Leitura implica uma } \\
\text { correspondência } & \text { entre } \\
\text { conhecimento prévio do leitor } \\
\text { e os dados fornecidos pelo } \\
\text { texto. }\end{array}$ & $\begin{array}{l}\text { A leitura é } \\
\text { constituída de } \\
\text { etapas. }\end{array}$ & $\begin{array}{l}\text { A leitura está } \\
\text { centrada na visão } \\
\text { de linguagem } \\
\text { como interação. }\end{array}$ & $\begin{array}{l}\text { A leitura deve ser } \\
\text { realizada a partir de } \\
\text { textos simples para } \\
\text { os textos de maior } \\
\text { complexidade. }\end{array}$ & $\begin{array}{l}\text { A leitura permite } \\
\text { refletir sobre } \\
\text { questões da } \\
\text { realidade que } \\
\text { cercam o aluno. }\end{array}$ \\
\hline $\begin{array}{l}\text { - A leitura encontra sua razão } \\
\text { de ser na busca pelas } \\
\text { transformações da realidade. }\end{array}$ & $\begin{array}{l}\text { O leitor realiza } \\
\text { um trabalho ativo } \\
\text { de construção do } \\
\text { significado do } \\
\text { texto. }\end{array}$ & $\begin{array}{l}\text { Leitura leva à } \\
\text { interação entre } \\
\text { textos e discursos. }\end{array}$ & $\begin{array}{c}\text { A leitura para } \\
\text { entender as } \\
\text { demandas sociais. }\end{array}$ & $\begin{array}{l}\text { A leitura permite } \\
\text { ao aluno buscar } \\
\text { informações e } \\
\text { orientações para } \\
\text { solucionar } \\
\text { problemas. }\end{array}$ \\
\hline $\begin{array}{l}\text { - Leitura, tem-se o leitor como } \\
\text { coprodutor do texto. }\end{array}$ & $\begin{array}{l}\text { O leitor tem } \\
\text { objetivos de } \\
\text { leitura. }\end{array}$ & $\begin{array}{l}\text { Leitura deve levar } \\
\text { à formação do } \\
\text { leitor crítico. }\end{array}$ & $\begin{array}{l}\text { A leitura de vários } \\
\text { gêneros deve ser } \\
\text { contemplada. }\end{array}$ & $\begin{array}{l}\text { A leitura deve } \\
\text { considerar as } \\
\text { experiências dos } \\
\text { leitores/alunos. }\end{array}$ \\
\hline $\begin{array}{l}\text { - Possibilite o crescimento e o } \\
\text { desenvolvimento de um aluno- } \\
\text { leitor crítico. }\end{array}$ & $\begin{array}{l}\text { A leitura implica } \\
\text { compreensão. }\end{array}$ & - & $\begin{array}{l}\text { A leitura é mais que } \\
\text { uma atividade de } \\
\text { decodificação. }\end{array}$ & $\begin{array}{l}\text { A leitura vai além } \\
\text { da decodificação. }\end{array}$ \\
\hline $\begin{array}{l}\text { - Elaborando uma } \\
\text { compreensão através das } \\
\text { trocas de conhecimentos e } \\
\text { informações realizadas pelos } \\
\text { participantes do discurso. }\end{array}$ & $\begin{array}{l}\text { A leitura é } \\
\text { concebida como } \\
\text { uma forma de } \\
\text { interação. }\end{array}$ & - & $\begin{array}{l}\text { A leitura implica } \\
\text { estratégias de } \\
\text { seleção, } \\
\text { antecipação, } \\
\text { inferência e } \\
\text { verificação. }\end{array}$ & $\begin{array}{l}\text { A leitura envolve } \\
\text { dimensões } \\
\text { linguística textual, } \\
\text { discursiva dentre } \\
\text { outras. }\end{array}$ \\
\hline $\begin{array}{l}\text { - A leitura produto é pessoal, } \\
\text { individual, determinada pelas } \\
\text { condições sociais, culturais, } \\
\text { históricas, afetivas e } \\
\text { ideológicas do leitor. }\end{array}$ & - & - & $\begin{array}{l}\text { A leitura pode ser } \\
\text { trabalhada por meio } \\
\text { das diferentes } \\
\text { sugestões didáticas. }\end{array}$ & $\begin{array}{c}\text { A leitura deve } \\
\text { focar na } \\
\text { consolidação do } \\
\text { gosto pela leitura e } \\
\text { no } \\
\text { desenvolvimento } \\
\text { da compreensão do } \\
\text { texto. } \\
\end{array}$ \\
\hline $\begin{array}{l}\text { - Promove o diálogo entre as } \\
\text { diferentes concepções de } \\
\text { leitura. }\end{array}$ & - & - & - & $\begin{array}{l}\text { A leitura envolve } \\
\text { relações } \\
\text { intertextuais. } \\
\end{array}$ \\
\hline- & - & - & - & $\begin{array}{l}\text { A leitura deve } \\
\text { levar o aluno a ler } \\
\text { criticamente a } \\
\text { realidade. }\end{array}$ \\
\hline
\end{tabular}

Fonte: Elaboração própria.

Ao observar a tendência maior dos documentos pelo viés interacionista no trato da leitura é possível refletir sobre o papel dessa forma de leitura para o processo educacional. Para os PCN e
PCNEM (BRASIL, 1998; 2000), ensinar português nos níveis fundamental e médio só faz sentido com base em textos orais e escritos, buscando uma interação entre leitura, produção de texto e análise 
linguística. A leitura é uma das práticas que compõem o ensino e a aprendizagem da língua materna e, ao verificar que os documentos a constitui como interação, como um processo que perpassa etapas e que deve levar à formação de um sujeito crítico, consequentemente, é possível que as atividades de escrita e de análise linguística também sigam tal viés dialógico.

Caso o professor, respaldado pelos documentos, centrado na perspectiva interacionista, desenvolva em sala práticas de leitura que levem ao diálogo, ao compartilhar de informações, às práticas intertextuais, demarcando questões de escrita e de análise linguística no material lido, ele possibilitará ao aluno se configurar como sujeito de seu dizer. Logo, por meio da leitura como um processo são contempladas as outras práticas, respondendo àquilo que os documentos esperam, possibilitando ao aluno constituir-se como sujeito ativo diante das práticas sociais com quais se depara em seu cotidiano. Isso justifica, então, os dizeres de Geraldi (2008, p. 88) quando afirma que: "o ensino de língua portuguesa deveria centrar-se em três práticas: leitura de textos; produção de textos; e análise linguística”.

Logo, cabe ao profissional de Língua Portuguesa refletir sobre o papel dessas perspectivas de leitura no processo educacional, uma vez que, os documentos aqui em análise devem ser compreendidos como uma proposta para melhor atender as necessidades do ambiente escolar. Já que "o ensino da leitura e da escrita é umas das principais tarefas da escola" (MENEGASSI; FUZA, 2010, p. 316).

Todos os autores declararam não haver qualquer potencial conflito de interesses referente a este artigo.

\section{REFERÊNCIAS}

BAKHTIN, M. Estética da criação verbal. 4. ed. São Paulo: Martins Fontes, 2003.

BRASIL, SEF. Parâmetros Curriculares Nacionais: Língua Portuguesa: $5^{\text {a }}$ a $8^{\mathrm{a}}$. Série. Brasília: SEF, 1998.

BRASIL, SEM. Parâmetros Curriculares Nacionais: Língua Portuguesa: $1^{\text {a }}$ a $3^{\text {a }}$. Série. Brasília: SEM, 2000.

CELLARD, A. A análise documental. In: POUPART, J.; DESLAURIERS, J. P; GROULX, L. H.; LAPERRIÈRE, A.; MAYER, R.; PIRES, A. P. A pesquisa qualitativa: enfoques epistemológicos e metodológicos. Petrópolis: Vozes, 2008.

DELL'ISOLA, R. L. P. A interação sujeitolinguagem em leitura. In: MAGALHÃES, I. (org.). As múltiplas faces da linguagem. Brasília: UNB, 1996.

FIAD, R. S. Mesa Redonda: Práticas de leitura e escrita em sala de aula. 15 de junho de 2012. In: $2^{\circ}$ CIELLI - Colóquio Internacional de Estudos Linguísticos e Literários $5^{\circ}$ CELLI - Colóquio de Estudos Linguísticos e Literários. Universidade Estadual de Maringá. Maringá, 2012.

FULGÊNCIO, L.; LIBERATO, Y. A leitura na escola. São Paulo: Contexto, 1996.

FUZA, A. F. Os conceitos de leitura da Prova Brasil. 2010, 108 p. Dissertação (Mestrado em Letras) Universidade Estadual de Maringá, Maringá, 2010. GERALDI, J. W. O texto na sala de aula.3. Ed. São Paulo: Ática, 2008.

KATO, M. A. No mundo da escrita: uma perspectiva psicolinguística. São Paulo: Ática, 1990.

KLEIMAN, A. Oficina de leitura: teoria e prática. Campinas: Pontes, 2010.

Texto e leitor: aspectos cognitivos da leitura. 7. ed. Campinas, SP: Pontes, 2000.

LEFFA, V. J. Aspectos da leitura. Porto Alegre: Sagra Luzzano, 1996.

MAGALHÃES, I. As múltiplas faces da linguagem. Brasília: UNB 1996.

MENEGASSI, R. J; FUZA, A. F. F. O Conceito de Leitura nos Documentos Oficiais. SIGNUM: Estud. Ling., Londrina, n. 13/2, p. 315-336, dez. 2010. 
MENEGASSI, R. J. Perguntas de leitura. In: $\overline{167-189 .}$ Leitura e ensino. Maringá: Eduem, 2010, p.

.; ANGELO, C. M. P. Conceitos de leitura. In: MENEGASSI, R. J. (Org). Leitura e ensino. Maringá: Eduem, 2005, p. 15-40.

SILVA, J. R. S.; ALMEIDA, C. D.; GUINDANI, J. F. Pesquisa documental: pistas teóricas e metodológicas. Revista Brasileira de História \& Ciências Sociais, ano I, n. 1, p. 1-15, julho, 2009.

SILVA, E. T. Leitura crítica e suas fronteiras: ensaios. Campinas. Mercado de Letras, ALB, 1998.

TOCANTINS, SEDUC. Referencial Curricular do Ensino Fundamental - Língua Portuguesa. Tocantins, 2009a.

TOCANTINS, SEDUC. Proposta Curricular do Ensino Médio - Língua Portuguesa. Tocantins, 2009b.

ZYGMANTAS, J.; FREITAS, I. C. C. A. $A$ Avaliação da Aprendizagem em Livros Didáticos de Inglês.2003/2004. Disponível em: <http://www.apliesp.org.br>. Acesso em: 26 abr. 2014. 